\title{
Production of $\boldsymbol{\gamma}-\mathrm{Al}_{2} \mathrm{O}_{3}$ from Kaolin
}

\author{
Seyed Ali Hosseini*, Aligholi Niaei, Dariush Salari \\ Department of Applied Chemistry, Faculty of Chemistry, University of Tabriz, Tabriz, Iran

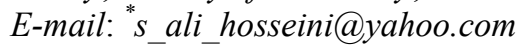 \\ Received April 21, 2011; revised June 8, 2011; accepted July 12, 2011
}

\begin{abstract}
The paper reports a process for synthesis of $\gamma$-alumina from kaolin. Kaolin was transformed to meta-kaolin by calcination at $800^{\circ} \mathrm{C}$ for $2 \mathrm{~h}$. $\gamma$-alumina powder was synthesized through extracting alumina from metakaolin via $\mathrm{H}_{2} \mathrm{SO}_{4}$ and meta-kaolin reactions and consequently precipitation in ethanol, which led to form the aluminum sulfate. The precipitated aluminum sulfate was dried and calcined at $900^{\circ} \mathrm{C}$ for $2 \mathrm{~h}$, which resulted the formation of $\gamma$-alumina. The structure of $\gamma$-alumina was confirmed by XRD and FTIR and the mean particles size of $\gamma$-alumina was determined by SEM to be $0.5-0.9 \mu \mathrm{m}$. The study revealed the kaolin could be promising material for preparation of $\gamma$-alumina.
\end{abstract}

Keywords: Kaolin, $\gamma$-Alumina, Aluminum Sulfate, Calcination

\section{Introduction}

Alumina has enormous technological and industrial application. It exists in a variety of meta-stable structures including $\gamma^{-}, \eta-, \delta-, \theta-, \kappa$ - and $\chi$-aluminas, as well as its stable $\alpha$-alumina phase [1]. Bauxites have been widely used in industry to produce alumina via the Bayer process. On the other hand, nonbauxitic materials, which are more abundant in many countries than bauxite resources, also have been processed in attempts to develop alternative technologies for producing alumina [2-4].

Some examples of nonbauxitic raw materials are alunite, sillimanite, andalusite, kyanite, kaolin, mica, and fly ash. Significant advances in alumina purity have been achieved using materials such as sulfates, nitrates, and chlorides as alumina precursors, to obtain high purity alumina [5-8].

Among various structures for alumina, $\gamma$-alumina is one kind of extremely important nano sized materials. It is used as a catalyst and catalyst substrate in automotive and petroleum industries, structural composites for spacecraft, and abrasive and thermal wear coatings [9]. Recent studies have shown that $\gamma$-alumina is thermo dynamically stable relative to $\alpha$-alumina when a critical surface area is achieved [10], and that nano $\gamma$-alumina powder can promote the sintering behaviour of alumina and silicon carbide fibbers [11], and also that the use of single phase of $\gamma$-alumina powders makes the densification temperature shift to lower temperature as compared with the sample consisting of $\gamma$ - and $\chi$-alumina [12].
Those outcomes can open up endless possibilities for the applications of $\gamma$-alumina, so it is of significance to investigate the preparation of $\gamma$-alumina. Until now, a large variety of methods such as sol-gel synthesis from calcination of boehmite [9], poly hydroxo aluminum-poly vinyl alcohol [10], laser ablation of an aluminum target in an oxygen atmosphere [13], hydrolysis of alumina alkoxide [14], thermal decomposition of aluminum sulfate [15], metal organic chemical vapor deposition with $\mathrm{Al}\left(\mathrm{CH}_{3}\right)_{3}[16]$ have been used to prepare $\gamma$-alumina.

Kaolinite is a clay mineral, part of the group of industrial minerals, with the chemical composition $\mathrm{Al}_{2} \mathrm{Si}_{2} \mathrm{O}_{5}(\mathrm{OH})_{4}$. It is a layered silicate mineral, with one tetrahedral sheet linked through oxygen atoms to one octahedral sheet of alumina octahedral [17]. Kaolin contains 20 - 26 percent by weight of alumina. Therefore, it can be suitable material for production of $\gamma$-alumina because of its abundance and having considerable content of alumina in kaolin structure. In this study we report a production of $\gamma$-alumina from kaolin using a simple and commercial method. All materials used in this methods, are relatively cheap and are found in industrially scale.

\section{Experimental}

\subsection{Instrumentation}

X-ray diffraction (XRD) studies were carried out on a Siemens D500 diffractometer, working with the $\mathrm{K}_{\alpha}$ line of copper $(k=0.154 \mathrm{~nm})$. Measurements of the samples were 
carried out in the range $2 \theta$ of $0^{\circ}-70^{\circ}$, at a scanning rate of $1 \%$ min. Infrared (IR) spectra were recorded with a Bruker 27 FT-IR spectrometer using the Universal ATR Accessory in the range from 3650 to $400 \mathrm{~cm}^{-1}$ with $4 \mathrm{~cm}^{-1}$ resolution. SEM characterization of gamma alumina was carried out with scanning electron microscopy (model EQ-C1-1). The composition of materials was analyzed by $\mathrm{X}$-ray fluorescence spectroscopy (spectro MIDEX).

\subsection{Synthesis}

The Kaolin, used as a starting material was supplied from Zonoz mines (Marand, Iran). The chemical composition of Zonoz kaolin is given in Table 1. After extracting from mine and grinding the kaolin, it was ground in an agate mortar to particles below $0.5 \mathrm{~mm}$ in size. The powdered kaolin was calcined at $800^{\circ} \mathrm{C}$ for $2 \mathrm{~h}$ in an electric furnace to loosen the alumina components. Then, the kaolin powder was dispersed in a $2.0 \mathrm{~N} \mathrm{H}_{2} \mathrm{SO}_{4}$ solution to attain a solid/liquid ratio of $1: 20$ by weight. The mixture of kaolin powder and acid $(250 \mathrm{~mL})$ was contained in a $500 \mathrm{~mL}$ round flask. The reaction flask fitted with a reflux condenser and the mixture was mixed with magnetic stirrer for $18 \mathrm{~h}$. The temperature of mixture was set at $70^{\circ} \mathrm{C}$.

After the mixture of kaolin and acid had been leached, it was cooled to room temperature and filtered to remove leach residue, which mainly consisted of silica. The filtered leach liquor then was added dropwise at a rate of $6.0 \mathrm{~mL} / \mathrm{min}$ into $600 \mathrm{~mL}$ of ethanol while the ethanol was stirred with a magnetic stirrer. Ethanol was used as a precipitating agent because aluminum sulfate can be selectively precipitated by ethanol from the ionic solution [1]. The precipitates were washed again with the ethanol and with distilled water and then dried at $70^{\circ} \mathrm{C}$ for $10 \mathrm{~h}$. Finally, the precipitates were calcined at $900^{\circ} \mathrm{C}$ for $2 \mathrm{~h}$ in an electric furnace.

\section{Results and Discussion}

Figure 1 shows the XRD pattern of kaolin and calcined

Table 1. Chemical composition of marand kaolin.

\begin{tabular}{cc}
\hline Material & Weight percentage \\
\hline $\mathrm{SiO}_{2}$ & 61.5 \\
$\mathrm{Al}_{2} \mathrm{O}_{3}$ & 24.5 \\
$\mathrm{Fe}_{2} \mathrm{O}_{3}$ & 0.55 \\
$\mathrm{CaO}$ & 1.55 \\
$\mathrm{Na} 2$ & 0.8 \\
$\mathrm{MgO}$ & 0.6 \\
L.O.I & 10 \\
\hline
\end{tabular}

kaolin $\left(800^{\circ} \mathrm{C}\right)$. It is observed that the kaolin shows all the characteristic peaks of kaolinite. On calcination, these peaks disappear giving a featureless band of X-ray amorphous meta-kaolin. Kaolin-type clays undergo a series of phase transformations upon thermal treatment in air at atmospheric pressure. Endothermic dehydroxylation (or alternatively, dehydration) begins at $550^{\circ} \mathrm{C}$ $600^{\circ} \mathrm{C}$ to produce disordered meta-kaolin, $\mathrm{Al}_{2} \mathrm{Si}_{2} \mathrm{O}_{7}$, but continuous hydroxyl loss $(-\mathrm{OH})$ is observed up to $900^{\circ} \mathrm{C}$ and has been attributed to gradual oxolation of the metakaolin [18]. In this study, calcination of kaolin at $800^{\circ} \mathrm{C}$ led to form the meta-kaolin, which is transient and more active and reacts easier than kaolin. Equation (1) shows the changes during calcination and formation of metakaolin. During the calcination the structure of kaolin was degraded and two molecule waters were released.

$$
\mathrm{Si}_{2} \mathrm{O}_{5}(\mathrm{OH})_{4} \mathrm{Al}_{2} \rightarrow \mathrm{Al}_{2} \mathrm{Si}_{2} \mathrm{O}_{7}+2 \mathrm{H}_{2} \mathrm{O}
$$

During the leaching of meta-kaolin in sulphuric acid, the alumina in meta kaolin is extracted and dissolves in $\mathrm{H}_{2} \mathrm{SO}_{4}$ which leads to formation of aluminum sulfate (Equation (2)).

$$
\begin{gathered}
\mathrm{Al}_{2} \mathrm{O}_{3}(\text { in metakaolin })+3 \mathrm{H}_{2} \mathrm{SO}_{4} \rightarrow \\
2 \mathrm{Al}^{3+}+3 \mathrm{SO}_{4}^{2-}+3 \mathrm{H}_{2} \mathrm{O}
\end{gathered}
$$

Addition of aluminum sulfate in ethanol led to precipitate the aluminum sulfate, as shown in Equation (3).

$$
\begin{gathered}
\mathrm{Al}^{3+}+3 \mathrm{SO}_{4}^{2-}+3 \mathrm{H}_{2} \mathrm{O} \rightarrow \mathrm{Al}_{2}\left(\mathrm{SO}_{4}\right)_{3} \cdot 3 \mathrm{H}_{2} \mathrm{O} \\
\mathrm{Al}_{2}\left(\mathrm{SO}_{4}\right)_{3} \cdot 3 \mathrm{H}_{2} \mathrm{O} \stackrel{\Delta\left(900^{\circ} \mathrm{C}\right)}{\longrightarrow} \gamma-\mathrm{Al}_{2} \mathrm{O}_{3}
\end{gathered}
$$

Evaporation of ethanol and consequently calcination in $900^{\circ} \mathrm{C}$ led to transform the aluminum sulfate to $\gamma$ alumina (Equation 4). XRF analysis confirmed the high purity of $\gamma$-alumina ( $98 \%$ by weight) and the other metal oxides and also $\mathrm{SiO}_{2}$ were trace. It has been reported in literature that decomposition of aluminium sulfate occur at temperature range $680^{\circ} \mathrm{C}-1030^{\circ} \mathrm{C}[1,19]$.

The results of XRD analysis of resulted sample confirmed the formation of $\gamma$-alumina through comparing with JCPDS 29-63. The result of the analysis is shown in Figure 2. The characteristic peaks of $\gamma$-alumina are

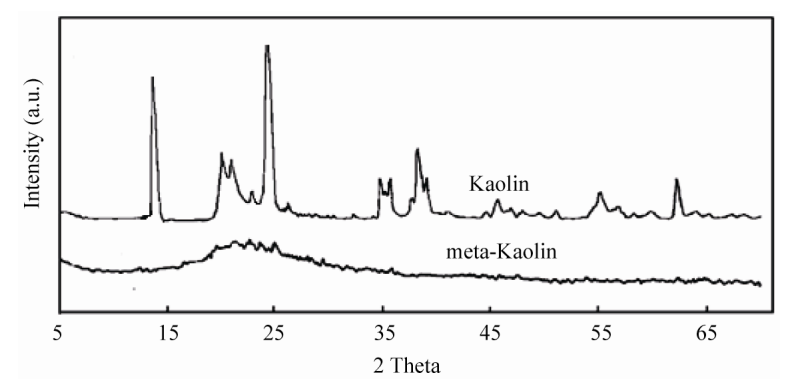

Figure 1. XRD pattern of kaolin and meta-kaolin. 


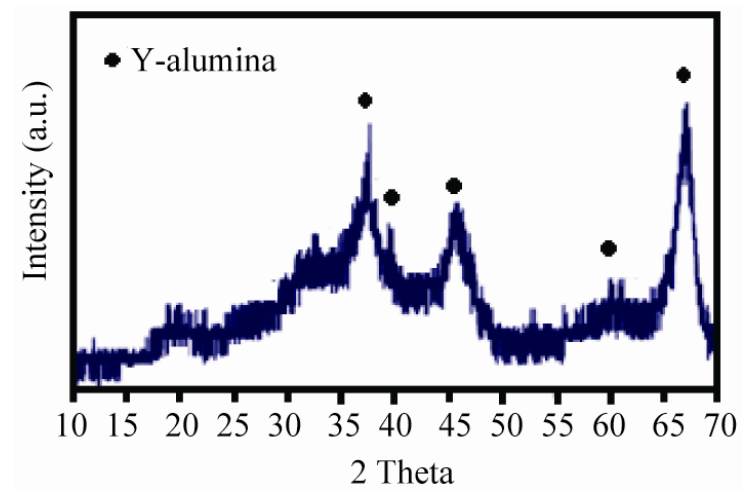

Figure 2. XRD pattern of synthesized gamma-alumina.

shown in the figure. In addition, the formation of $\gamma$-alumina was approved by FTIR spectrum (Figure 3). Reference [20] showed that $\gamma$-alumina is known to have a spinel structure which exists over a range of hydrogen content captured by the empirical formula $\mathrm{H}_{3 \mathrm{~m}} \mathrm{Al}_{2-\mathrm{m}} \mathrm{O}_{3}$. According to this result, the IR spectra of Figure $\mathbf{3}$ obtained in our experiment could be readily explained.

The stronger broadening band $3800-3000 \mathrm{~cm}^{-1}$ occurs due to the hydrogen bond between the various hydroxyl groups in the product. The stronger broadening band $1000-400 \mathrm{~cm}^{-1}$ correspond to Al-O vibration existed under the temperature of $750^{\circ} \mathrm{C}$, one of which was between $1000-500 \mathrm{~cm}^{-1}$, the other between $500-400$ $\mathrm{cm}^{-1}$.

The particle sizes of synthesized gamma alumina were determined by Scanning electron microscopy. The SEM images are shown in Figure 4. The resulted particles are in the range of $0.5-0.9$ micrometer.
As we know, gamma alumina is used as catalyst and catalyst support because of its higher specific surface area and thermal stability. $\gamma$-alumina is stable until temperature of $1030^{\circ} \mathrm{C}$. It has been reported that the thermal stability of $\gamma-\mathrm{Al}_{2} \mathrm{O}_{3}$ was greatly improved in the presence of some additives such as alkaline-earth ions, rare-earth ions, silicon and phosphor or a combination of both [21]. $\mathrm{Si}$ was more effective than other elements in stabilizing alumina and significantly retarded the transformation of $\gamma-\mathrm{A}_{2} \mathrm{O}_{3}$ into $\alpha-\mathrm{A}_{2} \mathrm{O}_{3}$. The presence of $\mathrm{TiO}_{2}$ could also improve the thermal stability of alumina [22,23].

\section{Conclusions}

$\gamma$-alumina powders were successfully synthesized by alumina extraction processes through reaction of metakaolin with $\mathrm{H}_{2} \mathrm{SO}_{4}$ solution. Direct precipitation in ethanol was a crucial step for synthesis of $\gamma$-alumina. It is concluded that kaolin can be used as promising material to preparation of $\gamma$-alumina. In agreement with other works, it is resulted that the main factor in obtaining of different alumina phases is the calcination temperature. Calcination at $680^{\circ} \mathrm{C}-1030^{\circ} \mathrm{C}$ leads to form the $\gamma$-alumina [1].

\section{Acknowledgements}

The authors wish to thank Tabriz pharmaceutical Technology Incubator for encouraging support and Mr. Reza Masomi from Tabriz University of Medicine Science for his assistance in obtaining of kaolin.

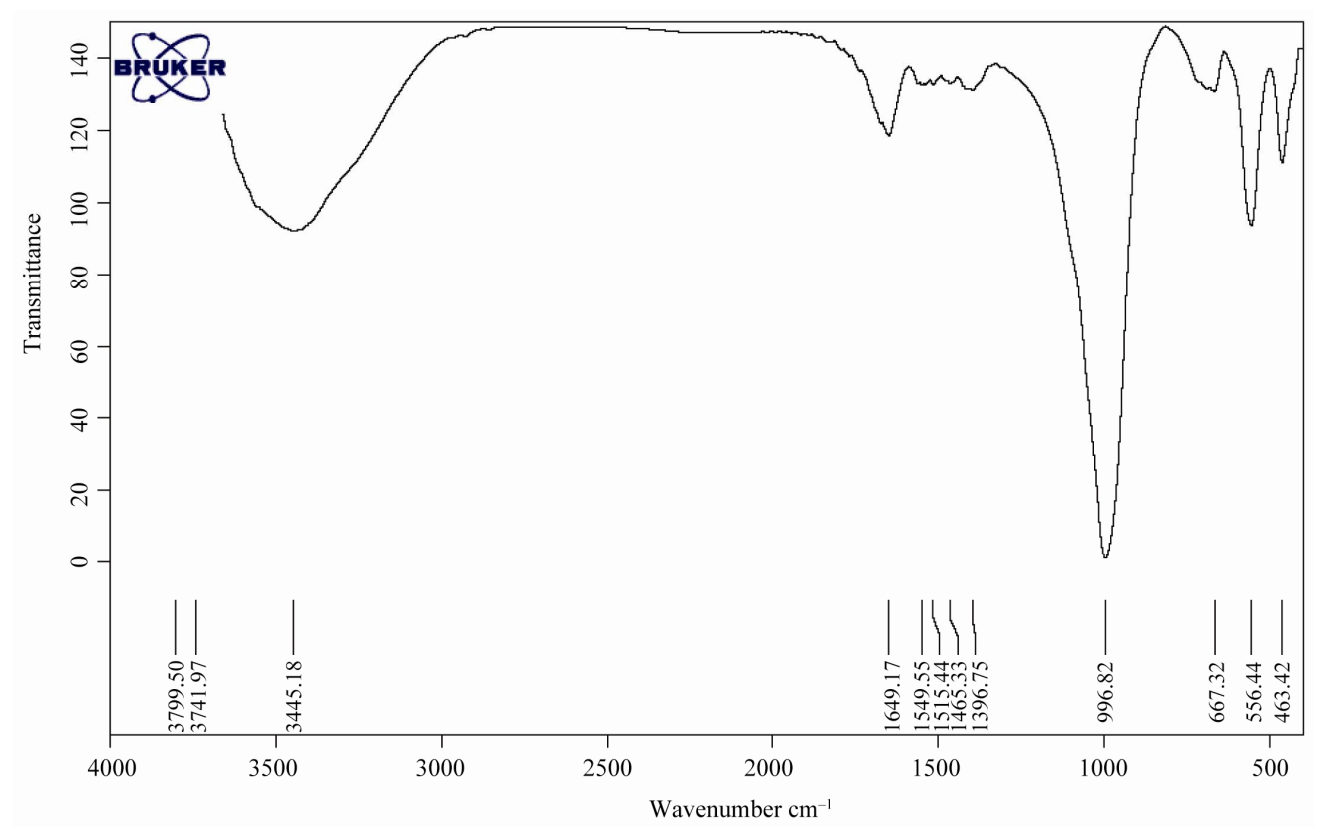

Figure 3. FTIR spectrum of synthesized gamma-alumina. 


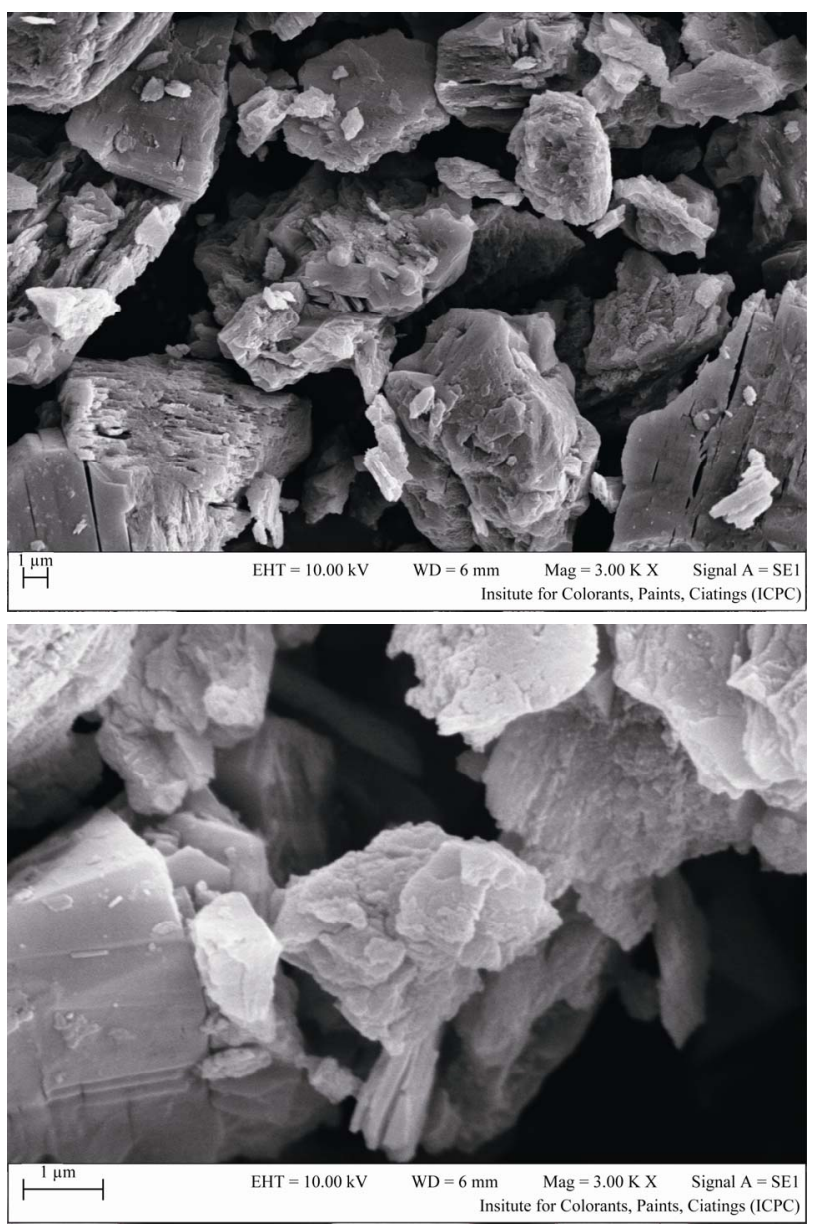

Figure 4. SEM image of synthesized gamma-alumina.

\section{References}

[1] S. Wang, X. Li, S. Wang, Y. Li and Y. Zhai, "Synthesis of Gamma-Alumina via Precipitation in Ethanol," Materials Letters, Vol. 62, No. 20, 2009, pp. 3552-3554. doi:10.1016/j.matlet.2008.03.048

[2] W. Gitzen, "Aluminas as Ceramic Material," American Ceramic Society, Columbus, 1970.

[3] J. McColm, "Ceramic Science for Materials Technologist," Chapman and Hall, New York, 1983.

[4] H. H. Murray, "Traditional and Newapplications for Kaolin, Smectite, and Palygorskite: A General Overview," Applied Clay Science, Vol. 17, No. 5-6, 2000, pp. 207211.

[5] R. H. Zhao, F. Guo, Y. Q. Hu and H. Q. Zhao, "SelfAssembly Synthesis of Organized Mesoporous Alumina by Precipitation Method in Aqueous Solution," Microporous and Mesoporous Materials, Vol. 93, No. 1-3, 2006, pp. 212-216.

[6] E. Kato, K. Diamon, M. Nanbu, "Decomposition of Two Aluminum Sulfates and Characterization of the Resultant Aluminas," Journal of the American Ceramic Society, Vol. 64, No. 8, 1981, pp. 436-443. doi:10.1111/j.1151-2916.1981.tb09892.x

[7] J. E. Blendell, H. K. Bowen and R. L. Coble, "Effects of Particle Distribution on Transformation-Induced Toughening in an MgO-PSZ," American Ceramic Society Bulletin, Vol. 63, 1984, pp. 799-804.

[8] F. W. Dynys and J. W.,Halloran, "Alpha Alumina Formation in Alum-Derived Gamma Alumina,"Journal of the American Ceramic Society, Vol. 65, No. 9, 1982, pp. 442-448. doi:10.1111/j.1151-2916.1982.tb10511.x

[9] G. Paglia, C. E. Buckley, A. L. Rohl, R. D. Hart, K. Winter and A. J. Studer, "Boehmite Derived $\gamma$-Alumina System. 1. Structural Evolution with Temperature, with the Identification and Structural Determination of a New Transition Phase, $\gamma$-Alumina," Chemistry of Materials, Vol. 16, No. 2, 2004, p. 220. doi:10.1021/cm034917j

[10] Y. H. Wang, J. Wang, M. Q. Shen and W. L. Wang, "Synthesis and Properties of Thermostable $\gamma$-Alumina Prepared by Hydrolysis of Phosphide Aluminum," Journal of Alloys and Compounds, Vol. 467, No. 1-2, 2009, pp. 405-412.

[11] K. M. Parida, A. C. Pradhan, J. Das and N. Sahu, "Synthesis and Characterization of Nano-Sized Porous Gamma-Alumina by Control Precipitation Method," Materials Chemistry and Physics, Vol. 113, No. 1, 2009, pp. 244248.

[12] Y. Yajima, M. Hida, S. Taruta and K. Kitajima, "Pulse Electric Current Sintering and Strength of Sintered Alumina Using $\gamma$-Alumina Powders Prepared by the Sol-Gel Method," Journal of the Ceramic Society of Japan, Vol. 111, No. 1294, 2003, pp. 419-425. doi:10.2109/jcersj.111.419

[13] G. P. Johnston, R. Muenchausen, D. M. Smith, W. Fahrenholtz and S. Foltyn, "Reactive Laser Ablation Synthesis of Nanosize Alumina Powder," Journal of the American Ceramic Society, Vol. 75, No. 12, 1992, pp. 3293-3298. doi:10.1111/j.1151-2916.1992.tb04424.x

[14] T. Ogihara, H. Nakagawa, T. Yanagawa, N. Ogata and K. Yoshida, "Preparation of Monodisperse, Spherical Alumina Powders from Alkoxides," Journal of the American Ceramic Society, Vol. 74, 1991, p. 2263.

[15] E. Kato, K. Daimon and M. Nanbu, "Decomposition of Two Aluminum Sulfates and Characterization of the Resultant Aluminas," Journal of the American Ceramic Society, Vol. 64, 1981, p. 436.

[16] H. Noda, K. Muramoto, and H. Kim, "Preparation of Nano-Structured Ceramics Using Nanosized $\mathrm{Al}_{2} \mathrm{O}_{3}$ Particles," Journal of Materials Science, Vol. 38, No. 9, 2003, pp. 2043-2047. doi:10.1023/A:1023553925110

[17] W. A. Deer, R. A. Howie and J. Zussman, "An Introduction to the Rock-Forming Minerals," 2 Edition, Longman, Harlow, 1992.

[18] M. Bellotto, A. Gualtieri, G. Artioli and S. M. Clark, "Kinetic Study of the Kaolinite-Mullite Reaction Sequence. Part I: Kaolinite Dehydroxylation," Physics and Chemistry of Minerals, Vol. 22, No. 4, 1995, pp. 207-214. doi:10.1007/BF00202253

[19] J. H. Park, S. W. Kim, S. H. Lee, H. S. Kim, S. S. Park 
and H. C. Park, "Synthesis of Alumina Powders from Kaolin with and without Ultrasounds," Journal of Materials Synthesis and Processing, Vol. 10, No. 5, 2002, pp. 289-293.

[20] K. Sohlberg, S. J. Pennycook and S. T. Pantelides, "Hydrogen and the Structure of the Transition Aluminas," Journal of the American Ceramic Society, Vol. 121, 1999, p. 7493.

[21] C. Belver, M. A. B. Munoz and M. A. Vicente, "Chemical Activation of a Kaolinite under Acid and Alkaline Conditions," Chemistry of Materials, Vol. 14, No. 5, 2002, pp. 2033-2043. doi:10.1021/cm0111736
[22] Q. Liu, A. Q. Wang, X. H. Wang, W. D. Guo and T. Zhang, "Synthesis, Characterization and Catalytic Applications of Mesoporous $\gamma$-Alumina from Boehmite Sol," Microporous and Mesoporous Materials, Vol. 111, No. 1-3, 2008, pp. 323-333. doi:10.1016/j.micromeso.2007.08.007

[23] S. X. Zhou, M. Antonietti and M. Niederberger, "Low-Temperature Synthesis of $\gamma$-Alumina Nanocrystals from Aluminum Acetylacetonate in Nonaqueous Media," Small, Vol. 3, No. 5, 2007, pp. 763-767. doi:10.1002/smll.200700027 